\title{
Tico ROMAO \\ Cinematic Hybridity: \\ Graphic Design and the End Title Sequence
}

\begin{abstract}
This article contends that graphic design principles play a key role in the creation of title sequences in films and although distinct from generic and narrative filmmaking norms, are complementary to mainstream narrative filmmaking aims. In addition, this article makes the case for a relevance-theoretic framework to the analysis of title and end titles sequences where the contextual and figurative dimensions of certain sequences require a sensitivity to pragmatic factors that are difficult to theoretically accommodate within a semiotic framework. This article demonstrates the utility of a relevance-theoretic approach through an analysis of the end title sequence of Black Panther (Ryan Coogler 2018). The article concludes with a reflection upon the differing narrative functions of the end title sequence as compared to an opening title sequence and how instead of acting in an expository capacity (such as foreshadowing certain themes) they often figuratively recap themes in a particularly visually salient form.
\end{abstract}

Keywords: Graphic design, Title sequences, Pragmatics, Implicature, Metaphor.

\section{Tico ROMAO}

MacEwan University

romaot@macewan.ca

EKPHRASIS, 2/2019

CROSSING NARRATIVE BOUNDARIES BETWEEN CINEMA AND OTHER MEDIA

pp. 169-189

DOI:10.24193/ekphrasis.22.10

Published First Online: 2019/11/27
There is a broad recognition within film studies that the production of title sequences and end title sequences for mainstream films is normally outsourced to design companies. Often invoked alongside this recognition is a notion of authorship where individual designers are additionally identified as the main creators of such title and end title sequences. Deborah Allison, for instance, cites Olivier Kuntzel and Florence Deygas of Nexus Productions as the designers of the title sequence of Catch Me If You Can (Steven Spielberg, 2012), and Jack Post identifies Richard Greenberg as the creator of the 
innovative title sequence for Altered States (Ken Russell, 1981) (Allison "Catch"; Post). Within film studies, Saul Bass has arguably achieved the status of title sequence auteur through his design of acclaimed title sequences such as Carmen Jones (Otto Preminger, 1954), Vertigo (Alfred Hitchcock, 1958), Anatomy of a Murder (Otto Preminger, 1959), North by Northwest (Alfred Hitchcock, 1959), Psycho (Alfred Hitchcock, 1960) and It's a Mad Mad Mad Mad World (Stanley Kramer, 1963). Dedicated monographs have been written on Bass's creative work in both film and design, as have a number of articles and interviews (Bass and Kirkham; Horak; Haskin and Bass; Emily King; Kirkham; Supanick). That mantle has recently turned to designer Kyle Cooper largely on the back of the critical acclaim directed toward his title design for Se7en (David Fincher, 1995). Identification of an authorial hand in the production of title sequences extends beyond Saul Bass and Kyle Cooper as most clearly evidenced by the website Art of the Title (http://www.artofthetitle. $\mathrm{com} /$ ) that celebrates not only distinguished title sequences but also the designers and studios involved in their production.

While authorship in some shape or form informs the production of title sequences, this singular focus upon star designers obscures the underlying design conventions they work with and innovate. Deborah Allison has compellingly argued that such sequences are better understood by reference to the filmmaking norms of a particular historical period ("Beyond"). In this article, I draw upon Allison's approach but contend that the norms in question are not only the governing generic and narrative film norms but the reigning design norms as well. Despite the acknowledgement in film studies that title sequences have been primarily produced by designers, analysis has not been sufficiently extended to the design principles they employ in the creation of such sequences. Such a gap in the relevant film studies literature is unsurprising given that the comparison between design and film has been for the most part unexplored whereas the hybridity with other media such as literature, theatre, vaudeville, photography, video games, and most recently comic books are routine (see, for example, Corrigan; Knopf; Jenkins; Guido and Lugon; King and Krzywinska; Burke).

This article has three aims. First, I contend that design principles play a key role in the creation of title sequences and although distinct from generic and narrative filmmaking norms, they have proven complementary to mainstream narrative filmmaking aims. Second, a case is made for a relevance-theoretic approach to the analysis of title and end title sequences in contrast to Michael Betancourt's recently advanced semiotic framework where the contextual and figurative dimensions of certain sequences require a sensitivity to pragmatic factors that are difficult to theoretically accommodate within his semiotic framework (Betancourt, "Semiotics and Tile Sequences"). Third, through an analysis of the end title sequence of Black Panther (Ryan Coogler, 2018), I demonstrate the utility of a relevance-theoretic approach that attends to both design and mainstream filmmaking norms informing 
title and end title sequences. The article concludes with a reflection upon the differing narrative functions of the end title sequence as compared to an opening title sequence.

\section{Medium Hybridity and Title Sequence Design Conventions}

Noël Carroll observes that medium specificity arguments pertaining to the film medium tend to consist of claims whereby certain film properties are considered distinct from other media, with these properties privileged over those that are perceived to be borrowed from other media. Such claims, Carroll notes, coincided with efforts to legitimate film as an art form during the period of the emergence of cinema ("Medium Specificity" 3). It is ironic then that the strongest evidence against medium specificity arguments tend to be found in historical investigations that demonstrate the extensive borrowing of conventions and techniques from antecedent art forms within the same period that affirms film's inherent hybridity. John Fell, for instance, has shown how film's storytelling conventions have been informed by techniques drawn from a variety of sources including theatre, Victorian pulp fiction novels, comics, painting, and photography (Film).

Such parentage also assumes the shape of more localized yet telling influences. Discussing the "soft style" of cinematography that prevailed in the 1920s, Kristin Thompson contends that the impulse was to imitate portrait photography to beautify the close shots of heroines, most notably those of Lillian Gish (in Bordwell, Staiger, and Thompson 289). In a different vein, Henry Jenkins demonstrates how anarchic comedies of the 1930s demonstrated a vaudeville aesthetic that was drawn from the performance conventions of variety theatre (Jenkins 59-71). Similar influences are observable at the level of soundtrack design. Bordwell notes how the symphonic film score drew from the compositional conventions of nineteenth century operatic and symphonic music that already exhibited a narrative proclivity (in Bordwell, Staiger, and Thompson 33-35). The Hollywood musical frequently adapted popular Broadway productions and, in the process, transferred musical theatre conventions of performance and dance into their song and dance routines (Altman 130-31). As popular music evolved over the course of the twentieth century, so did the influences on soundtrack design. Henry Mancini, along with other film composers, introduced the vernacular of jazz music into film scoring as used notably in the soundtrack of Touch of Evil (Orson Welles, 1958). With the introduction of the popular compilation score in films such as Easy Rider (Dennis Hopper, 1969), songs were used in conjunction with the image track, making the notion of hybridity quite literal (Smith 154-63). External influences may even extend to an individual filmmaker, Eric Lichtenfeld, for example, argues that the rapid cutting rate evidenced in The Rock (Michael Bay, 1996) derives from the director's previous experience producing music videos and commercials (Lichtenfeld 181). Additional examples of external influence from other media beyond those mentioned can be adduced. What these instances illustrate is that medium hybridity better describes the ontological properties of film than medium specificity. 
What is significant about such discussions of hybridity is that they have assisted in the identification of aesthetic norms derived from other media that have been incorporated into film. However, what is missing from these discussions is an account of the importation of graphic design norms into film, namely with respect to the production of intertitles, opening titles, and end title sequences. This importation into film additionally confers graphic design the status of a distinct medium with its own defining characteristics and domain of study, which Steve Baker asserts is the conjunctions of word and image (250). As the above investigations attest, attention to the production practices of the relevant historical period provides the most proximate context to not only identify these graphic design conventions at work but also examine how they "leave their marks" on the films themselves in ways that have a bearing on their intended meanings and spectatorial interpretation (Bordwell, Staiger, and Thompson xvii). One cannot extract the expressive dimensions of letterforms and the pictorial elements of title cards without references to the practices that produced them. Although The Classical Hollywood Cinema describes the narrative functions of title sequences and intertitles at length, there is no discussion of the graphic design conventions that informed their production (Bordwell 25-28 and Thompson 183-89, both in Bordwell, Staiger, and Thompson).

The most appropriate place to start analyzing the production practices of title sequences is during the emergence of cinema. Adam Duncan Harris contends that the first title sequences during the early silent period drew heavily from the conventions that informed the design of the title pages of books, theater programs, and lantern slide shows, which attests to their hybrid composition (12-25). The lantern slide shows that were often used to accompany early silent film screenings to provide brief story descriptions, and in some instances the names of a star who appeared in a film short. In the initial stages, titling emphasis was first directed to presenting the production company's logo as the film's most recognizable element. Yet the demand for lengthier fiction films coupled with the emergence of the star system as a means to attract audiences and the need for more detailed story and cast information made the use of the accompanying lantern slide shows quite impractical. As a result, such information began to migrate to the film itself, in the title sequences. Edwin S. Porter's Uncle Tom's Cabin (1903) was among the first films to feature title and expository cards (Harris 25-27; Musser 349). Such titles cards consisted of hand painted letterforms, normally on black cardboard, that over time started to feature illustrated backgrounds to provide additional information pertaining to the film's setting (Harris 27-30). As narrative feature films became longer title sequences became more complex. Billing lists became longer and more detailed, with star and production crew billing and title sequence order subject to contractual agreements (Ross 4-6). Fueling the demand for title sequences and expository titles even more, the parallel growth of newsreels required a great deal of explanatory text. In the face of such demands, ancillary film production firms developed, such as Pacific Titles, which took on such work from 
20th Century-Fox, MGM, and Warner Brothers, outsourcing title sequence production to them (Harris 52).

With the outsourcing of the production of title sequences to designers and design firms design conventions gained greater prominence in title and end title sequences. Allison contends that during the 1960s certain title sequences exhibited psychedelic imagery and stylistics, such as Arabesque (Stanley Donen, 1966) and Caprice (Frank Tashlin, 1967), which derived from psychedelia as a broader design and aesthetic movement (Promises 222-26). Allison also observes that the title sequences for Funny Face (Stanley Donen, 1957), in which Richard Avedon was credited for the main title backgrounds, and Portrait in Black (Michael Gordon, 1960) manifest compositional strategies that sought to invoke the design styles of magazine layouts (Promises 22526). While such intersections between graphic design and film are fascinating in and of themselves, they do not demonstrate the persuasiveness of graphic design conventions that are routinely used in title and end title sequence designs. To identify such conventions, it is important to recognize that graphic design encompasses a broad range of media in which it offers solutions for all text and background combinations, whether these include images or not. The main graphic design conventions informing the design of title and end title sequences are the following: 1) letter size and the order of credits on screen; 2) the placement of letters onto a background image; 3 ) the spatial relationship between letters and background; 4) the different forms of background used in title and end title sequences; 5) the visual communicative features of the letterforms; and 6) the impact upon brand design as model for title and end title sequence design. In all cases such conventions are not restricted to questions pertaining to title and end title sequence form, but also entail their semantic dimensions that impact upon how such sequences are interpreted.

The most widely discussed set of graphic design conventions are those that are tied to contractual agreements and serve what Betancourt describes as the 'crediting function' of title sequences (Title Sequences 29-30). This function relates to how contractual agreements stipulate the way credits are to appear in title and end title sequences. Harris indicates that title designers would set, as a general rule, the letter size of the film's title as a dimensional standard that dictated the letter size of the proceeding billing credits that would diminish in size proportionate to the contractual importance of the film production personnel in question. For instance, in an analysis of the title cards for It Happened One Night (Frank Capra, 1934) Harris observes that the letter size of credits for the film's stars is equal to that of the title, signaling the importance of their star billing. The next title card presents the film's writing credits, with the writer's names reduced to roughly $50 \%$ of the size of the star credits, with the other technical credits appearing on that card further proportionately reduced (Harris 46). Although contractually stipulated, considerations of the dimensions of credit letters are underpinned by graphic design principles pertaining to legibility (Pettersson 83-84) and their ability to direct attention, especially through additional 
considerations of colour (Winn 67-68). Contrasting letter size not only directs the viewer's gaze to those credits which have priority on a title card but can also maintain the viewer's attention on the credits when the background is sufficiently neutral and does not contain significant diegetic information.

The order of the credits was and continues to be subject to contractual stipulations as well. Although manifesting historical variations the standard credit order is as follows: production logo, main actors, supporting actors and technical personnel, and then, writer, producer and director (Allison Promises 68-69). Significantly, credit order and prominence not only serve a crediting function but can also alert the viewer to what Bordwell describes as the film's "narrative hierarchy;" the credit sequence offers a set of expectations as to a film's protagonists, antagonists, and secondary characters, often coupled with the spectator's knowledge of the profiles of the screen actors and their previous screen appearances (in Bordwell, Staiger, and Thompson 25). As Allison points out, these narrative expectations can be subverted to mislead the viewer, as in Sleuth (Joseph L. Mankiewicz, 1972) where 'Alec Cawthorne,' a fictitious actor, is given credit for the role of Inspector Doppler as a means to disguise the fact that the character Milo Tindale is impersonating a policeman (Promises 72).

The placement and arrangement of text in relation to the background, whether neutral or bearing still or moving image, usually falls within the domain of typography that Robert Waller defines as "the design and arrangement of printed text" (341). When combined with images the conventions that guide their holistic arrangement are what graphic designers normally categorize as layout principles. The design of title and end title sequences imported these conventions to assist in the placement of text within title cards and to determine their appropriate relation to the background. One dominant practice throughout film history, from the silent cinema to the advent of widescreen, formats was to center the text with respect to the screen as a means to provide graphic balance to the title card, but also to focus the viewer's attention primarily on the credits. One additional factor motivating this centered composition was the aim to place the credits within the 'safe-lettering zone,' constituting the middle two-thirds of the screen, to avoid titles being cut off in theaters that did not possess screens with a standard Academy ratio (Harris 87). However, with the arrival of widescreen formats and the gradual shift in the function of title sequences, which began to provide greater narrative exposition, Allison observes that text became increasingly decentered with title designers adopting new formal balancing schemes, to facilitate the greater prominence of the background images given its increasing diegetic nature (Promises 131-32). Such decentered titles provided "type holes" in which text could be placed in suitable areas that did not obscure significant narrative action depicted in the background, a strategy that designer Wayne Fitzgerald used in the title sequence for Touch of Evil (Betancourt Semiotics 32-33).

As Betancourt has correctly pointed out, text and image relations can be additionally semantic and factor into how title and end title sequences are to be 
interpretively understood. Betancourt advances a useful title sequence typology in which text and background relations fall into three modes: the figure-ground mode, where no semantic relations arise between text and background; the calligram mode, where a direct relationship between text and background is established, often as a way of identifying and naming actors and connecting them to the characters they portray in a film; and the rebus mode, where an indirect relationship is made between text and background, where both elements tangentially relate to each other to effect a metaphorical figure, often symbolically expressing the theme of the narrative to come, or, in end title sequences, to recapitulate the theme previously articulated (Semiotics). Historical conventions pertaining to particular periods of title sequence design inform all of these modes. Figure-ground strategies were popular from the 1920s to the 1950s. Backgrounds were either textured or consisted of still or moving images and, crucially, credit and expository functions were clearly separated, as in The Wizard of $\mathrm{Oz}$ (Victor Fleming, 1939) in which the rolling clouds background is disconnected from the credits superimposed upon it. Calligram strategies were particularly in vogue during the 1930s when actors' names were often accompanied by images of the actors in character, such as the vignettes in Grand Hotel (Edmund Goulding, 1932) which capture their character traits through expressive poses. Rebus strategies became particularly prominent during the 1950s and 1960s, largely under the influence of Saul Bass. The conventions of brand design were transferred into principles of title design, as in the title sequence for Psycho where the fracturing of the credit letterforms by the linear bars that intersect them constitutes a metaphor of psychosis that the film explores.

One specific aspect of text and image relations that distinguishes title and end title sequences from the main narrative body of the film is their distinctive spatial articulations. As Allison observes with regard to the title design of Catch Me If You Can (Steven Spielberg, 2003) and the 1950s and 1960s title designs that the sequence makes homage to, the frame appears two-dimensional and like a "flat canvas that attempts no illusion of scenic depth" (Allison "Catch Me" 5). Instead of articulating a diegetic space that possesses depth in order to stage narrative action many title and end title sequences configure a different form of space in a manner that is more akin to a two-dimensional poster where the superimposition of text over image or image over text generates depth cues through occlusion. The use of such spatial articulations is what graphic designers refer to as layering (Lupton and Phillips 127-35). That is apt since it expresses a different form of spatial arrangement and captures the processes involved in their design, particularly in contemporary digital compositing.

Four types of layering options predominate in title design. First and foremost is the dominant practice to simply superimpose credit text over a background, whether containing images or not, such as in Rio Bravo (Howard Hawks, 1959) where the title credits are layered over a live action sequence of a wagon train heading along a desert trail. Further enhancing the impression of depth in this sequence are the drop 
shadows of the letterforms, a visual effect used in typography to yield the perception that the letters are hovering over the background. The title sequence for The Terminator (James Cameron, 1984) offers a compelling set of innovations of this standard practice and illustrates how such conventions can be used to institute a complex creation of layered depth. Over a neutral black background, the film's title "Terminator" appears through letterforms that are transparent and possessing thick blue outlines that heavily protrude, offering additional depth cues to the arrangement, and are presented in such a large format that their size initially exceeds the dimensions of the frame. A partial view of the letter ' $R$ ' first appears from the left side of the screen and then a partial view of the letter ' $T$ ' next appears from the right with both letters sliding across the frame simultaneously in opposite directions and in a manner through which they overlap causing the letter ' $R$ ' to momentarily occlude the blue outlines of the letter 'T.' Then appear the billing credits, which are layered over the film title in such a way that when they materialize they occlude the letterforms of the film title behind them. This pattern continues until the word 'Terminator' is fully spelt out after which the full title of the film is revealed and becomes legible as it recedes into the background, adding an impression of depth to the black background itself. The title sequence consequently manifests four layers - the background (itself possessing an impression of depth), the film title letterforms moving to the right, the film title letterforms moving to the left, and the billing credits - creating a space that is not narratively scenic but one that is more stratigraphical in nature.

The second option concerns the cases in which the superimposing layer consists of images, whether live footage or animated. The title sequence for Blow Out (Brian De Palma, 1981) offers an interesting contrasting example where the soundtrack plays a more integral role and where the title sequence is itself a combination of title sequence forms. Over a neutral black background, the needle of a VU meter flutters in response to a sound mix consisting of wind, heartbeats, the fast forwarding of tape, screams and an imminent crash, all of which succinctly presage the narrative concerns of the film. When the billing credits first appear the needle of a VU meter flies over them, fleetingly occluding their letterforms, and then acts as a wipe to clear them to introduce the next set of credits. With the sound of a tire blowing out the letterforms of the film title emerge in enlarged form, individually and in rapid succession, visually mimicking the leakage of air. The film title reappears, this time in full view but dynamically moving forward towards the viewer to the sound of screeching tires, in a motion that causes the letters of 'Blow' to overlap with 'Out.' At that point the title sequence cuts to a live action scene inside a sound editing room that commences the film's story but with the billing credits continuing with the supporting cast and additional personnel simply superimposed over the scene. This title sequence consequently is more sequential in nature than that of The Terminator.

The third option is to use the credit letterforms as a mask through which they act as a window onto live action that is made visible to the viewer. The title design 
for Blow-Up (Michelangelo Antonioni, 1966) offers an interesting case of layering in which the credit text is superimposed over a shot of static background lawn. The credits announce "Premier Productions Co. Inc. Presents" with letterforms that are white and opaque and appear over the background lawn creating a layering effect similar to that of the title sequence in Rio Bravo. The next set of titles, however, present letterforms that act as a mask which offers partial and occluded views of a live action fashion photo shoot but accompanied by depth cues that are notably ambiguous. The black outline of the letterforms that produce their seeming dimensionality can either be perceived as extruding, jutting forward with the live action constituting their surface, or alternatively perceived as receding, as if cut into the earth itself with the live action appearing behind the lawn, a typographical play with illusion that thematically anticipates the theme of illusion explored in the film.

The fourth option is to insert all or of some of the title credits within the diegetic space of the narrative action, as does the title sequence for Bombay Talkie (James Ivory, 1970). Its title sequence commences with a live action shot presenting the cityscape of Bombay and then zooms out and pans leftward to reveal a busy intersection where a group of men are carrying a poster stating "Merchant Ivory Productions Presents Bombay Talkie." Next the title sequence presents a montage of billboards situated in the city that provide the remaining billing credits, which are illustrated in the fashion of contemporaneous Bollywood film posters. At the same time, they function in an expository capacity by establishing the diegetic setting of the film's ensuing story, additionally reinforced by the film's raga-based theme tune that ethnically anticipates the narrative action. In this title sequence one finds a union of the credit and expository functions that are integrated into one single layer by subsuming the credits into a diegetic world, an act that displaces their inherent tension onto that which resides in any self-conscious narration, that is the tension between the enunciation and the enunciated.

In addition, there are different forms of backgrounds used in title and end title sequences that graphic designers normally consider with respect to figure/ground relationships (Lupton and Phillips 85). In her empirical analysis of title sequences Allison contends that eight main types of backgrounds have manifested themselves over the history of titling in the Hollywood cinema: plain backgrounds; still picture backgrounds; introduction of characters; book pages; orchestra, where the opening credits play over an orchestra pit as an overture, as in The Man Who Knew Too Much (Alfred Hitchcock, 1956); animation; minimal movement, such as rolling clouds in the title sequence for The Wizard of $\mathrm{O} z$ that do not manifest any significant narrative action; and live action footage that offers significant narrative action, as in the title sequence for Touch of Evil (Allison, Promises 75-96). Allison demonstrates that in certain periods particular types of backgrounds were more prevalent than others, yet previous types still remained an option and were occasionally used in combination with other backgrounds, as in the title sequence for Blow Out. These background options are best 
understood as offering a spectrum of increasing degrees of integration of the crediting and expository function of title sequences. Neutral background is used to emphasize the crediting function over expository aims, whereas live action backgrounds are used to privilege narrative exposition instead. Live action backgrounds that are expository in nature are clearly narratively meaningful, but so are still picture backgrounds given that they normally include images that are narratively relevant, such as the illustration of a large panther used in the title sequence of Cat People (Jacques Tourneur, 1942). Even a black neutral background can be expressive, as illustrated by the first segment of the title sequence for All The President's Men (Alan J. Pakula, 1976) that lends expression to the serious subject matter of the Watergate scandal.

Along with the conventions governing background selection are the conventions that apply to the appropriate selection of the letterforms of the text to appear in title and end title sequences. Such decisions are inherent to typography as a discipline, especially in relation to considerations of the visual communicative features of the letterforms. With respect to letterforms in film title sequences, Harris contends that the conventions governing selection relate to their ability to convey the genre, setting and tone of a film (Harris 134-37). Certain letterforms possess generic dimensions through their recurrent association with a particular genre. Black Letter, also known as 'Old English,' is often used in title sequences of period adventure films such as The Adventures of Robin Hood (Michael Curtiz, 1938), whereas nineteenth century letterforms, like Antique or Egyptian, are normally associated with Westerns as exemplified by the titles for Santa Fe Trail (Michael Curtiz, 1940). As such examples attest, the association of letterforms with particular periods in history are also invoked in title sequences to signal the historical and cultural settings of the films in question. The Old English letterforms invoke the late middle ages, in which the legend of Robin Hood is situated, while the Egyptian letterforms for Santa Fe Trail intimate the American frontier. The use of Script in title sequences in melodramas and romantic comedies indicates how letterforms can participate in the creation of a mood that is elegant and evocative of sentiment, of which the scripted letterforms for My Best Friend's Wedding (P.J. Hogan, 1997) would be an example. The tilting of letterforms to be arranged on angles or curves in film comedies, as illustrated by the anarchic hand written titles for Those Daring Young Men in Their Jaunty Jalopies (Ken Annakin, 1969) also contribute to mood.

The final set of graphic design conventions applied to the production of title and end title sequences are those pertaining to the design of brands. Naomi Klein defines a brand as the "core meaning" of the corporation, and is normally imagistic in nature and metaphorically expressed (3). Jan-Christopher Horak describes a brand design as an ability "to create a cogent design element, image, or logo that could be utilized repeatedly across different media and had the ability to cement the identity of a product within that iconography" (65). This holds true particularly with the brand logos that Saul Bass designed for Quaker, AT\&T and Minolta, among other 
corporations. Bass describes his approach to designing title sequences in analogous terms as attempting "to reach for a simple, visual phrase that tells you what the picture is all about and evokes the essence of the story" (quoted in Kael 62). Within Bass's title work this "simple visual phrase" is often manifested as a metaphorical expression, be it the image of a jagged arm for The Man with the Golden Arm (Otto Preminger, 1955), that concisely expresses the theme of heroin addiction, or the image of a truncated body and sword for Saint Joan (Otto Preminger, 1957), an icon of Joan of Arc succinctly capturing her military leadership but also her downfall, images that were additionally used in these films' posters.

The set of graphic design conventions that inform title and end title sequence design described above explain their often recognized distinctiveness from the main body of the film. They are the decisive moments of self-consciousness as film artifact, which aesthetically showcase word and image relations, offer alternative forms of filmic space, utilize the unique communicative power of letterforms, and in certain notable instances, especially in Saul Bass's title work, they display the metaphorical attributes of an effective brand logo. Their attraction ultimately stems from the resulting hybridity of mixing graphic design principles with filmic forms.

\section{Semiotics vs. Relevance Theory}

Given their unique cross-modal combination of communicative forms - text, image, and soundtrack - title and end title sequences pose the question of the spectatorial comprehension of these sequences. The most extended discussion of this issue so far has been undertaken by Michael Betancourt in Semiotics and Title Sequences. Invoking Roland Barthes's account of the distinction between denotation and connotation and incorporating Michel Foucault's deconstruction of the discursive relations between text and image, Betancourt advances an account of title sequences as semiotically structured levels of meaning, varying from the denotative levels of text and image to the connotative levels of allegorical expressions. Betancourt does not acknowledge or address the previous and longstanding critiques of film semiotics that have cast doubt on the understanding of the communicative dimensions of visual media by resorting to linguistic terms (Prince 18-20, Currie 113-37). Such an oversight weakens the theoretical grounds of his framework. However, instead of rehearsing such criticisms my aim here is to evaluate the explanatory adequacy of his semiotic account of the comprehension of connotation and metaphor within the specific context of watching opening and end title sequences.

Essential to Betancourt's semiotic account is the manner in which he attempts to effect a distinction between denotation and connotation as they apply to the visual domain. In a discussion of Barthes's use of these terms, denotation is designated as the process of recognition of images with connotation applying to their symbolic dimension: "The shifting levels Barthes identifies [...] correspond[s] to the movement between distinct recognitions of imagery in the painting and their transition from those 
depictions to become symbolic, suggesting allegorical interpretations" (Betancourt Semiotics 8). This distinction is reiterated again in the analysis of a scene from the film The House on Skull Mountain (Ron Honthaner, 1974) in which a skull is briefly superimposed over a woman looking into a mirror, which Betancourt describes as a conversion from "imagistic denotation to allegorical connotation" (Semiotics 17). The problem with this conflation of connotation with the symbolic is that it overlooks other forms of meaning routinely manifested in title and end title sequences. Consider the title sequence for The Adventures of Robin Hood. It would be inaccurate to say that the illustrated images of swords, bows, horns, coats of arms and archers appearing in the background metaphorically symbolize the historical medieval setting of the film. If one understands metaphor in its standard sense, whereby a concept (tenor) is understood through the qualities of another concept (vehicle) (Whittock $5-6)$, then it would be odd to claim that the viewer is being cued to understand the medieval period through the attributes of these illustrated objects. Instead, the title sequence simply presents a set of depicted objects that are historically associated with the medieval era to better generically guide the viewer toward the typical setting of the swashbuckler adventure film. The same can be said for the communicative dimensions of the Old English letterforms through which the title and credit details are conveyed in the sequence. The viewer is not being prompted to attend to the features of the letterforms themselves as a means to metaphorically apprehend the medieval era in a fresh and novel way. Like the background images, the Old English letterforms are associated with the film's historical period and to generically guide the viewer. Betancourt seems to be alert to such considerations of meaning-engendering when he states that "in connotation one finds the linkages provided by cultural associations and the emergent meanings provided by the strictly historical context" (Semiotics 15). Yet such "cultural associations" function in manifestly different ways than "allegorical connotations" and possess different underlying modes of meaning generation, a distinction that is not sufficiently recognized and worked out in his framework.

As noted earlier, metaphor looms large in Betancourt's typology of title sequences as a means to distinguish the rebus mode from the other text-image relations that characterize the figure-ground and calligram title sequence modes. Betancourt describes the rebus mode as that which "transforms depiction [...] into a sign whose meaning is other than depiction" (Semiotics 91), a process in which "allegory transforms representation into metaphor" (Semiotics 92). At issue here are the precise processes through which such transformations arise and how they are to be explained within a semiotic theoretical account. Semiotics works best as an explanatory framework in which meaning is generated through decoding operations that function within a broader "language" system that pairs signifiers with their semantic representations, their signifieds. However, it is unclear though how connotation functions within this system either as a cultural association or as a metaphor by resorting to processes 
that are situated internally to the system as opposed to factors that are external to it. One needs to ask by whose agency are these cultural associations and metaphoric transformations made. Critically for these processes to work Betancourt invokes the figure of the competent and knowledgeable spectator, referring to the "mediating effects of the audience's past experience and knowledge" (Semiotics 11) a figure he implicitly invokes again in relation to understanding the metaphorical dimensions of the rebus mode as that which requires "cultural lexia established by past knowledge and experience" (Semiotics 79). It is the competent and knowledgeable spectator who in the end is undertaking the explanatory heavy lifting with respect to connotation and metaphor as opposed to semiotic operations that are internal to a signifying system.

Cultural associations, historical context, and spectatorial experience and knowledge are terms that are more affiliated with the field of pragmatics than semiotics, in which linguistics is the source conceptual framework (Forceville 5259; Sperber and Wilson 9-15). ${ }^{1}$ A relevance-theoretic account is instead based upon pragmatic principles in which the comprehension of title and end title sequences takes place in contexts in which images and music are often ambiguous or polysemic, and in ways that do not lend themselves to be understood through decoding operations. A relevance-theoretic account also asserts that the communicative intentions of the filmmakers play a significant role in these processes. In addition, rather than continuing to employ the concept of connotation, with its expansive sense of "cultural associations," the concept of implicature is adopted to refer to the implicit meanings of an utterance, narrowing down the relevant associations to be considered (Sperber and Wilson Relevance 34-36). Within a pragmatics framework, connotation and implicit meaning refers to the same semantic phenomena. However, the concept of implicature better explains how cultural associations arise in the first place. A concept is a mental schema that consists of networks of information activated when one experiences that concept's indexical reference, or experiences representations thereof, in specific social contexts (Mandler 2-3). Through repeated communication and exposure such mental schemas are disseminated and become shared mental schemas within a specific culture (Sperber 33). Instead of considering cultural associations as some form of expanded lexicon that exists in an unspecified cultural system, they should be understood as implicatures deriving from ostensive acts that prompt specific schemas and activate specific networks on the basis of inference and relevance to the specific communicative context.

With respect to the comprehension of title and end title sequences, implicature refers to the implicit meaning produced by any ostensive feature of a sequence, be it the letterforms of the text, the graphic properties of the background, illustrated or animated images, live action footage, or the soundtrack. As was previously suggested, illustrated images and Old English letterforms function in the The Adventures of Robin Hood title sequence as implicatures that narrow down the range of generic possibilities 
as to which genre the film is to be attributed. Such attributions are based upon the viewer's possession of a shared mental schema of title sequences, which includes the trait that they normally act in this guiding capacity. In short, an implicature can derive from any feature of the sequence that participates in the generation of implicit meaning and which the spectator infers on the basis of shared mental schemas and contextual knowledge that best agree with the filmmakers' communicative intentions.

A relevance-theoretic framework can also provide an account as to how the metaphoric dimensions of certain title and end title sequences are comprehended by the spectator. Beyond implicature, which entails the inference of implicit meaning by the film viewers on their own volition and according to shared mental schemas, the comprehension of a metaphorical expression entails the recognition of a communicative intention by the filmmakers that cues the addressee to recognize the non-standard use of the expression and interpret it accordingly (Sperber and Wilson "A Deflationary Account of Metaphors" 87-90). To illustrate this point, consider again the title sequence for Psycho. The film's title and credits are not presented in a standard manner but are fractured by the linear bars that graphically intersect them and which cause sections of their letterforms to shift, momentarily hindering their legibility. Such a non-standard presentation of credits constitutes an explicit prompt to the spectator to not merely denotatively read them with respect to their crediting function but to interpret the splitting of the letterforms as metaphoric of psychosis itself, apprehended as a form of splitting that narratively prefigures the split personality of the Norman Bates character who is the thematic center of the film. Assisting in the apprehension of this metaphorical figure is Bernard Herrmann's prelude music. Its jarring and dissonant chords constitute emotive implicatures that provide the appropriate emotional equivalent of the title sequence and the film itself by means of their affective congruence with the graphic visuals of the splitting letterforms. In such ways a relevance-theoretic framework can model the spectatorial comprehension of title and end title sequences with respect to their medium hybridity and cross-modal complexity.

\section{Black Panther, Pragmatics, and Metaphoric Narrative Reframing}

The release of Black Panther has spawned numerous critical analyzes concerning its identity politics and depiction of the African diaspora best exemplified by Image $\mathcal{E}$ Text publishing a themed section of articles on the film (Karam and KirbyHirst). Significantly, these issues extend into the film's end title sequence making it particularly well suited to a relevance-theoretic analysis. As the eightieth instalment of Marvel Cinematic Universe (MCU) the film draws its iconography and characters from its comic book origins and retains Black Panther's alternate identity as T'Challa king of Wakanda, a fictional African country (Wiacek 17). Coogler's film adaptation focuses in particular on $T^{\prime}$ Challa's ascension to the throne making transition a key theme of the film. At the level of plot, this theme is expressed as the change 
in Wakanda's leadership from King T'Chaka - who was killed in a bomb blast in the previous MCU film Captain America: Civil War (Anthony Russo and Joe Russo, 2016) - thereby permitting his benevolent son, Prince T'Challa to become king. With this ascension also comes a change in Wakanda's political orientation from its past isolationism, which resulted in the neglect of the African diaspora, to a more paternalistic interventionist stance that acknowledges the ethical responsibilities of a technologically superior nation. Complicating this transition is Erik Killmonger, the film's antagonist, and product of the black American ghetto, who challenges King $\mathrm{T}^{\prime}$ Challa's right to the throne, and with it, T'Challa's paternalistic vision of Wakanda's place in the world. Killmonger, in contrast to T'Challa, envisions Wakanda as an exporter of weapons to bring about a revolution against racial oppression around the world. In a ritual battle that constitutes the film's turning point, $\mathrm{T}^{\prime}$ Challa is beaten by Killmonger, but returns at the film's climax to defeat Killmonger decisively and to resume his proper place as king.

The end title sequence for Black Panther consists of five distinct sections: the main computer animated title sequence at the end of which the film title appears; a secondary epilogue in which King $\mathrm{T}^{\prime}$ Challa announces that Wakanda will end its isolation from the rest of the world; the remaining technical credits presented over a neutral black background; a post-credit sequence customary of MCU instalments that links the film to the series; and, lastly, the Marvel Studios logo. The first segment exhibits a "simple visual phrase" that is metaphorical in its intent with its interpretation bound up with the film's theme song All the Stars, by Kendrick Lamar and SZA, which plays over the sequence and is thematically relevant. In its entirety the first segment contains text and images which work together to produce a metaphorical figure that encapsulates the main theme of transition which narratively dominates the film.

It is this theme of transition that the first segment of the end title sequence revisits and metaphorically expresses, but in the different visual register of computergenerated animation. What prompts the recognition of this metaphorical expression, in addition to the shared mental schema that end title sequences often function in a metaphorical recapping capacity, is the emphasis on transformation and transience that is manifested in both the credit letterforms and the visuals, a correspondence that is not coincidental. This correspondence is consequently an ostensive act by the filmmakers to prompt the viewers to interpret these parallel elements metaphorically. The letterforms, for instance, do not merely appear on the screen, but transition from the logography of a Wakandan script, providing implicatures of a previous era, to a Beyno typeface that is similar to letterforms associated with sci-fi films, offering implicatures of the future in an Afrofuturist manner (Tselentis). Accompanying these letterform transformations are visuals that depict representative iconography from the film, leading actors in character, and morphing graphic patterns that pulsate to the music, but as if all are constituted from the medium of vibranium sand. This aesthetic was first introduced in the film's opening prologue that explains the outer 
space origins of Wakanda's vibranium riches but functions in a more non-narrative capacity in the end title sequence. The use of sand as medium of construction in itself provides implicatures of impermanence but this impermanent state is further reinforced by images of characters disintegrating by either force of wind or in one striking image of a hand being punctured by the sheer weight of a ringed necklace. In such ways, the theme of transition manifested at the level of plot is read through the attributes of the typographic transformations and images of disintegration and is apprehended anew as a state of impermanence, in a manner that undercuts the sense of permanence which the return to narrative equilibrium through $T^{\prime}$ Challa's resumption to the throne was intended to signal.

This reinterpretation of the film's narrative is also manifested at the level of the lyrics of the music played over the first segment of the end title sequence that offer additional implicatures of implicit meaning. If $\mathrm{T}^{\prime} \mathrm{Challa}$ and Killmonger narratively represent opposing stances towards colonialism and ways to aid the African diaspora, then such stances are metaphorically restaged as SZA's chorus versus Kendrick Lamar's verse. $T^{\prime}$ Challa's vision of increased inclusivity and engagement with the outside world is metaphorically re-expressed through SZA's refrain "all the stars are closer," imagery invoking celestial proximity, whereas Killmonger's understandable bitterness towards racial oppression finds re-expression through Lamar's confrontational lyrics with the line "I hate people that feel entitled" applying not just to white privileged but towards the privileges of the noblesse oblige of the tribal elders who rule Wakanda (Williams). Whereas in the main story $\mathrm{T}^{\prime}$ Challa's vision prevails over Killmonger's worldview, in the end title segment, however, the lyrical metaphoric re-expression rebalances these opposing views to represent the utopian and dystopian dimensions of Afrofuturism itself. Such reinterpretations indicate that the expository function of opening title sequences, normally understood as the setting up of the story to come, does not apply to end title sequences for the reason that they can no longer anticipate a story that is already now known to the viewer. Instead of facilitating anticipation, end title sequences alternately offer the opportunity to provide a recapitulation of the narrative just witnessed that can either reaffirm the themes through metaphorical re-expression, such as the exploded views of Iron man's bodysuit in Iron Man (Jon Favreau, 2008), reiterating its theme of prosthetic extension, or metaphorically reframe the themes through an extrapolation of their premises, as does the end title sequence for Spider-Man: Into the Spider-Verse (Bob Persichetti, Peter Ramsey, and Rodney Rothman, 2018) by presenting and endlessly replicated SpiderMan in a series of seemingly endless kaleidoscopic vignettes. The Blank Panther title sequence goes even farther. It metaphorically reframes the themes in a manner that contradicts their earlier expression in the main body of the narrative. 


\section{Conclusion}

In this article I have contended that the concept of medium hybridity better describes the ontological properties of film rather than the concept of medium specificity. In addition, I have shown how previous accounts of cinematic hybridity have failed to acknowledge the ways in which opening title and end title sequences are informed by graphic design conventions that derive from a distinct design medium that is best defined as the domain of word and image relations. I have also highlighted the limitations of a semiotic framework when it comes to explaining the implicit and metaphoric meanings of opening and end title sequences and have shown how such meanings are better accounted for through a relevance-theoretic approach that emphasizes instead shared metal schemas, implicatures, ostensive acts, and communicative intentions. The utility of assuming a relevance-theoretic approach was demonstrated through an analysis of the end title sequence of Black Panther where the parallels between credit letterforms and the visuals constituted a non-diegetic prompt for the viewer to interpret the sequence metaphorically in relation to the theme of impermanence, which additionally reframed the film's return to narrative equilibrium as an act that possessed less resolution as initially presented. In do so, such a narrative reframing illustrates that end title sequences can function in ways distinct from the standard expository functions of opening title sequences. Clearly further studies of end title sequences are required to confirm the extent to which the functions of opening title and end title sequences differ, as well as studies that examine the design of title sequence conventions in other moving image media beyond that of film.

\section{Note}

1. An advocate of film semiotics could retort, as Warren Buckland does, that semiotics does not restrict itself to systems found in natural languages but appeals to all forms of communication that are based on systems, and is consequently capable of incorporating the explanatory principles of pragmatics (5-11). However, the explanatory principles of pragmatics are radically different from those advanced by semiotics as traditionally conceived and it is questionable whether an emphasis upon underlying systems on its own is sufficient in distinguishing semiotics from other approaches to communication. Consequently, a theoretical framework based upon them would be at best semiotic in name only. In a parallel manner, once one appeals to higher level operations such as interpretation to account for the comprehension of metaphor, as does Betancourt (Semiotics 84), one can legitimately ask in what ways such metaphors are "coded" in the semiotic sense of the term.

\section{Works Cited}

Allison, Deborah. "Catch Me If You Can, Auto Focus, Far from Heaven and the Art of Retro Title Sequences." Senses of Cinema, 26 May 2003.

----. Promises in the Dark: Opening Title Sequences in American Feature Films of the Sound Period. University of East Anglia, 2001. 
----. "Beyond Saul Bass: A Century of American Film Title Sequences." Film International, Jan. 30, unpaginated, 2011. http://filmint.nu/?p=202. Accessed 16 Nov. 2019.

Altman, Rick. American Film Musical. Indiana University Press, 1987.

Baker, Steve. "A Poetics of Graphic Design?" Visible Language, vol. 28, no. 3. Spring 1994, pp. 245-59.

Bass, Jennifer and Pat Kirkham. Saul Bass: A Life in Film and Design. Laurence King Publishing, 2011.

Betancourt, Michael. Title Sequences as Paratexts: Narrative Anticipation and Recapitulation. Routledge, 2018.

----. Semiotics and Title Sequences: Text-Image Composites in Motion Graphics. Routledge, 2017. Black Panther. Directed by Ryan Coogler. Walt Disney Studios Motion Pictures, 2018.

Bordwell, David, Janet Staiger and Kristin Thompson, editors. The Classical Hollywood Cinema: Film Style \& Mode of Production to 1960. Routledge, 1985.

Buckland, Warren. The Cognitive Semiotics of Film. Cambridge University Press, 2000.

Burke, Liam. The Comic Book Film Adaptation: Exploring Modern Hollywood's Leading Genre. University Press of Mississippi, 2015.

Carroll, Noël. "Medium Specificity Arguments and Self-Consciously Invented Arts: Film, Video, and Photography," Theorizing the Moving Image, Cambridge University Press, 1996.

Corrigan, Timothy, editor. Film and Literature: An Introduction and Reader, 2nd ed. Routledge, 2012.

Currie, Gregory. Image and Mind: Film, Philosophy and Cognitive Science. Cambridge University Press, 1995.

Fell, John L. Film and the Narrative Tradition. University of Oklahoma Press, 1974.

Forceville, Charles. "Relevance Theory as Model for Analyzing Visual and Multimodal Communication," Visual Communication, edited by David Machin, De Gruyter Mouton, 2014, pp. 51-70.

Guido, Laurent and Olivier Lugon, editors. Between Still and Moving Images: Photography and Cinema in the 20th Century. John Libbey Publishing, 2012.

Harris, Adam Duncan. Extra Credits: The History and Collection of Pacific Title and Art Studio, Diss. University of Minnesota, 2000.

Haskin, Pamela and Saul Bass. "'Saul, Can You Make Me a Title?': Interview with Saul Bass," Film Quarterly, vol. 50, no. 1, 1996, pp. 10-17.

Horak, Jan-Christopher. Saul Bass: Anatomy of Film Design. The University Press of Kentucky, 2014.

Jenkins, Henry. What Made Pistachio Nuts? Early Sound Comedy and the Vaudeville Aesthetic. Columbia University Press, 1992.

Kael, Pauline. "One, Two, Three by Billy Wilder," Film Quarterly, vol. 15, no. 3, Spring 1962, pp. 62-65.

Karam, Beschara and Mark Kirby-Hirst, guest editors. Themed Section: Black Panther and Afrofuturism, Image \& Text, no. 33, 2019. 
King, Emily. "Taking Credit: Saul Bass, Otto Preminger and Alfred Hitchcock," Design and Popular Entertainment. Edited by Christopher Frayling and Emily King. Manchester University Press, 2009, pp. 123-41.

King, Geoff and Tanya Krzywinska, editors. Screenplay: Cinema/Videogames/Interfaces. Wallflower Press, 2002.

Kirkham, Pat. "Reassessing the Saul Bass and Alfred Hitchcock Collaboration," West 86th: A Journal of Decorative Arts, Design History, and Material Culture, vol. 18, no. 1, SpringSummer 2011, pp. 50-85.

Klein, Naomi. No Logo: Taking Aim at the Brand Bullies. Alfred A. Knopf, 2000.

Knopf, Robert, editor. Theater and Film: A Comparative Anthology. Yale University Press, 2005.

Lichtenfeld, Eric. Action Speaks Louder: Violence, Spectacle, and the American Action Movie, revised ed. Wesleyan University Press, 2007.

Lupton, Ellen and Jennifer Cole Phillips. Graphic Design: The New Basics. Princeton Architectural Press, 2008.

Mandler, Jean. Stories, Scripts, and Scenes: Aspects of Schema Theory. Lawrence Erlbaum Associates, 1984.

Musser, Charles. The Emergence of Cinema: The American Screen to 1907. University of California Press, 1990.

Pettersson, Rune. Information Design 4 - Graphic Design. International Institute for Information Design, 2015.

Post, Jack. "From Altered States to Altered Titles: A Close Analysis of the Title Sequence to Ken Russell's Altered States (1981)." Journal of British Cinema and Television, vol. 12, no. 4, 2015, pp. 556-71.

Prince, Stephen. "The Discourse of Pictures: Iconicity and Film Studies." Film Quarterly, vol. 47, no. 1, Autumn 1993, pp. 16-28.

Ross, Murray. "Labor Relations in Hollywood." The Annals of the American Academy of Political and Social Science, vol. 254, November 1947, pp. 58-64.

Smith, Jeff. The Sounds of Commerce: Marketing Popular Film Music. Columbia University Press, 1998.

Sperber, Dan. Explaining Culture: A Naturalistic Approach. Blackwell, 1996.

Sperber, Dan and Deidre Wilson. "A Deflationary Account of Metaphors." The Cambridge Handbook of Metaphor and Thought. Edited by Raymond W. Gibbs Jr. Cambridge University Press, 2008, pp. 84-105.

----. Relevance: Communication and Cognition, $2^{\text {nd }}$ ed. Blackwell, 1995.

Supanick, Jim. "Saul Bass...To Hit the Ground Running..." Film Comment, vol. 33, no. 2, March-April 1997, pp. 72-77.

Tselentis, Jason. "Behind the Scenes: The Typography of "Black Panther"" Printmag, July 2, unpaginated, 2018. https://www.printmag.com/typography/the-typography-of-blackpanther/. Accessed 9 Nov. 2019. 
Waller, Robert. "Typography and Discourse." Handbook of Reading Research, vol. II. Edited by Rebecca Barr, Michael L. Kamil, Peter B. Mosenthal, P. David Pearson. Routledge, 1991, pp. 341-80.

Whittock, Trevor. Metaphor and Film. Cambridge University Press, 1990.

Wiacek, Stephen. Marvel Black Panther: The Ultimate Guide. Dorling Kindersley, 2018.

Williams, Délice. "Three Theses about Black Panther." Africology: The Journal of Pan African Studies, vol. 11, no. 9, August 2018, pp. 27-30.

Winn, William. "Perception Principles." Instructional Message Design: Principles from the

Behavioral and Cognitive Sciences, $2^{\text {nd }}$ ed. Edited by Malcolm Fleming and W.H. Howard Levie, 1993, pp. 55-126.

\section{Filmography}

All The President's Men (Alan J. Pakula, 1976)

Altered States (Ken Russell, 1981)

Anatomy of a Murder (Otto Preminger, 1959)

Arabesque (Stanley Donen, 1966)

Black Panther (Ryan Coogler, 2018)

Blow Out (Brian De Palma, 1981)

Blow-Up (Michelangelo Antonioni, 1966)

Bombay Talkie (James Ivory, 1970)

Caprice (Frank Tashlin, 1967)

Captain America: Civil War (Anthony Russo and Joe Russo, 2016)

Carmen Jones (Otto Preminger, 1954)

Cat People (Jacques Tourneur, 1942)

Catch Me If You Can (Steven Spielberg, 2012)

Easy Rider (Dennis Hopper, 1969)

Funny Face (Stanley Donen, 1957)

Grand Hotel (Edmund Goulding, 1932)

Iron Man (Jon Favreau, 2008)

It Happened One Night (Frank Capra, 1934)

It's a Mad Mad Mad Mad World (Stanley Kramer, 1963)

My Best Friend's Wedding (P.J. Hogan, 1997)

North by Northwest (Alfred Hitchcock, 1959)

Portrait in Black (Michael Gordon, 1960)

Psycho (Alfred Hitchcock, 1960)

Rio Bravo (Howard Hawks, 1959)

Saint Joan (Otto Preminger, 1957)

Santa Fe Trail (Michael Curtiz, 1940)

Se7en (David Fincher, 1995) 
Sleuth (Joseph L. Mankiewicz, 1972)

Spider-Man: Into the Spider-Verse (Bob Persichetti, Peter Ramsay and Rodney Rothman, 2018)

Those Daring Young Men in Their Jaunty Jalopies (Ken Annakin, 1969)

Touch of Evil (Orson Welles, 1958)

Uncle Tom's Cabin (Edwin S. Porter, 1903)

Vertigo (Alfred Hitchcock, 1958)

The Adventures of Robin Hood (Michael Curtiz, 1938)

The House on Skull Mountain (Ron Honthaner, 1974)

The Man Who Knew Too Much (Alfred Hitchcock, 1956)

The Man with the Golden Arm (Otto Preminger, 1955)

The Rock (Michael Bay, 1996)

The Terminator (James Cameron, 1984)

The Wizard of $\mathrm{Oz}$ (Victor Fleming, 1939)

Tico Romao is an instructor at MacEwan University. He has authored several publications and his research interests include film style, the action cinema, cognitive film theory, and social cognition. 